\title{
Response to Protocol Review Scenario: Reporting may vary
}

Judy Daviau, DVM, DACLAM

Thomas Jefferson University, Judith.Daviau@jefferson.edu

Troy Wilkins, BS

Follow this and additional works at: https://jdc.jefferson.edu/oarpp

Part of the Small or Companion Animal Medicine Commons

Let us know how access to this document benefits you

\section{Recommended Citation}

Daviau, DVM, DACLAM, Judy and Wilkins, BS, Troy, "Response to Protocol Review Scenario:

Reporting may vary" (2009). Office of Animal Resources papers and presentations. Paper 1.

https://jdc.jefferson.edu/oarpp/1

This Article is brought to you for free and open access by the Jefferson Digital Commons. The Jefferson Digital Commons is a service of Thomas Jefferson University's Center for Teaching and Learning (CTL). The Commons is a showcase for Jefferson books and journals, peer-reviewed scholarly publications, unique historical collections from the University archives, and teaching tools. The Jefferson Digital Commons allows researchers and interested readers anywhere in the world to learn about and keep up to date with Jefferson scholarship. This article has been accepted for inclusion in Office of Animal Resources papers and presentations by an authorized administrator of the Jefferson Digital Commons. For more information, please contact: JeffersonDigitalCommons@jefferson.edu. 


\title{
As submitted to Lab Animal and later published as:
}

\author{
Response to Protocol Review Scenario: Reporting \\ may vary \\ pp46 - 47 \\ Judy Daviau, DVM, DACLAM \& Troy Wilkins, \\ BS \\ doi:10.1038/laban0209-46b
}

\author{
Protocol Review \\ Lab Animal \\ Volume 38, No.2 February 2009
}

Reporting May Vary

Judy Daviau, DVM, DACLAM and Troy Wilkins, B.S.

Unfortunately for those of us in academic communities, we are sometimes faced with situations similar to those described in this protocol review. It is important that the IACUC be well versed in reporting procedures in order to prevent regulatory citations at a later date.

In this circumstance, Great Eastern University is dealing with an individual who has been a challenge to the IACUC. Although there is a great deal of history presented, it is important to consider the facts in the immediate scenario to make a decision on whether the incident is reportable. It is stated that a protocol violation occurred for which Dr. Banks voluntarily suspended any further animal work on the protocol. Larry Covelli, the IACUC chairman, agreed to inform OLAW. This action is appropriate as the Public Health Service Policy on Humane Care and Use of Laboratory Animals requires prompt reporting of any serious or continuing noncompliance with this Policy, any serious deviation from the provisions of the Guide or any suspension of an activity by the IACUC (PHS Policy IV.C. 6 \& 7 and IV.F. $3 \&$ 4). Therefore, even though the activity was not suspended by the IACUC, reporting is required due to the deviation from the approved protocol.

The question of whether of not this matter needs to be reported to the USDA is somewhat different. Even though hamsters are a regulated species, this does not in itself mandate reporting. The USDA requires notification when an activity has been suspended by the IACUC (9CFR Part 2, Subpart C 2.31(d)(7)). Since the IACUC has not yet suspended the activity, the threshold has not been breached. Voluntary suspension of work by the 
investigator is not addressed in the AWA, and discussions with our VMO have indicated that it is not reportable.

Reporting suspensions of animal activity to other funding sources can vary. It is imperative that the sponsorship agreement between the institution and the funding agency is reviewed for specific terminology on this issue. Again, Great Eastern needs to differentiate between a voluntary cessation of activity and an IACUC-mandated suspension. In reviewing recent CDC and DOD agreements at our university, the default terminology referred to the AWA requirements. Thus, in this case, voluntary cessation of activity would not be reportable.

It is important to remember that one caveat supersedes this entire discussion. Great Eastern University is bound by its PHS Assurance Statement. Reportable actions are clarified in that document. If Great Eastern has indicated that it will report all protocol violations to the funding agencies, it must abide by that statement and report this incidence. In addition, Great Eastern should consider what was stated in their previous correspondence with Dr. Banks. Due to the disagreement between committee members on the appropriate action to take in this incidence, if the IACUC previously threatened Dr. Banks with suspension, the committee may indeed want to suspend this activity for consistency. If so, then this becomes a reportable incident.

At our institution, we strive to provide the highest quality of compliance without overburdening the regulatory agencies with unnecessary reporting. Some instances are not clearly defined in the guidelines and may lead to differences of opinion. In these circumstances, we contact the appropriate agencies and request guidance. This has proved to clarify the expectations of the governing bodies and provide a liaison between our IACUC team and pertinent officials. Great Eastern University may choose to do this with the case of Dr. Banks in an effort to not only educate, but possibly unite the IACUC in their decision. Dr. Banks may be a difficult individual who will require IACUC-sanctioned actions to avoid further issues. The voluntary cessation of activity gives hope that Dr. Banks has an understanding of regulatory oversight and will strive to remain compliant in the future.

Judy Daviau is the Director of Animal Resources and Troy Wilkins is the IACUC Regulatory Affairs Manager at Thomas Jefferson University in Philadelphia, PA. 